\title{
ITER ECRH Upper Launcher Diamond Window - Qualification and Testing of a Protection Important Component
}

\author{
Sabine Schreck ${ }^{\mathrm{a}}$, Gaetano Aiello ${ }^{\mathrm{a}}$, Stefan Dieterle ${ }^{\mathrm{a}}$, Mario Gagliardi ${ }^{\mathrm{b}}$, Andreas Meier ${ }^{\mathrm{a}}$, \\ Gabriella Saibene ${ }^{\mathrm{b}}$, Theo Scherer $^{\mathrm{a}}$, Dirk Strauss ${ }^{\mathrm{a}}$ \\ ${ }^{a}$ Karlsruhe Institute of Technology, Institute for Applied Materials, Hermann-von-Helmholtz-Platz 1, \\ 76344 Eggenstein-Leopoldshafen, Germany \\ ${ }^{b}$ F4E, Josep Pla 2, Torres Diagonal Litoral B3, 08019 Barcelona, Spain
}

The diamond window is part of the ex-vessel waveguide system of the ITER ECRH Upper Launcher and consists of an ultra-low loss CVD diamond disk mounted in a system of metallic parts. On the one hand the window has to fulfil adequate transmission capability for high power mm-waves and on the other hand it serves, together with an isolation valve, as primary vacuum boundary of the ITER vacuum vessel, and has the function of tritium confinement. Therefore it is classified as Protection Important Component and high requirements for quality and safety apply. The window assembly cannot be entirely covered by codes and standards and thus an ad-hoc qualification program is required, including prototyping activities. The mm-wave transmission capability of the window, which is mainly defined by the dielectric loss of the diamond disk, has to be demonstrated as well as its structural integrity. For previous and current window prototypes, diamond disks with low dielectric losses have been chosen with a diameter of $80 \mathrm{~mm}$ and a thickness of $1.11 \mathrm{~mm}$. This thickness satisfies the resonance condition $(\mathrm{d}=\mathrm{n} * \lambda \mathrm{eff} / 2)$ for the $170 \mathrm{GHz}$ beam, ensuring a high transmission, but it also needs to be validated with respect to the mechanical loads, especially the expected pressure loads.

Investigations on the flexural strength of diamond disks $(D=30 \mathrm{~mm}, \mathrm{~d}=1.11 \mathrm{~mm})$ have been performed using a ring-onring set-up and the results lead to an estimation of the failure behavior.

In addition, pressure tests of a mock-up consisting of a diamond disk $(\mathrm{D}=80 \mathrm{~mm}, \mathrm{~d}=1.11 \mathrm{~mm})$ brazed to a copper cuff are under examination. The dedicated test program includes cyclic tests at lower pressures and high pressure tests (up to 2 bar) allowing a simulation of the expected events.

This paper will give an overview on the qualification activities for the ITER torus window with a focus on the qualification of the diamond disk and with respect to its mechanical properties. Respective parts of the test program, which need F4E and IO review and approval, will be described and first results will be presented.

Keywords: ITER, ECRH Upper Launcher (ECHUL), Diamond window, CVD, prototype, mock-up, pressure tests, flexural strength

\section{Introduction}

The ITER ECRH system consists of an equatorial launcher and four upper launchers. These are aimed at providing local current drive to stabilize NTMs by injecting up to $20 \mathrm{MW}$ of power at a frequency of $170 \mathrm{GHz}$ [1]. The diamond windows are located in the port cell environment between the launcher and the transmission lines (Fig. 1).

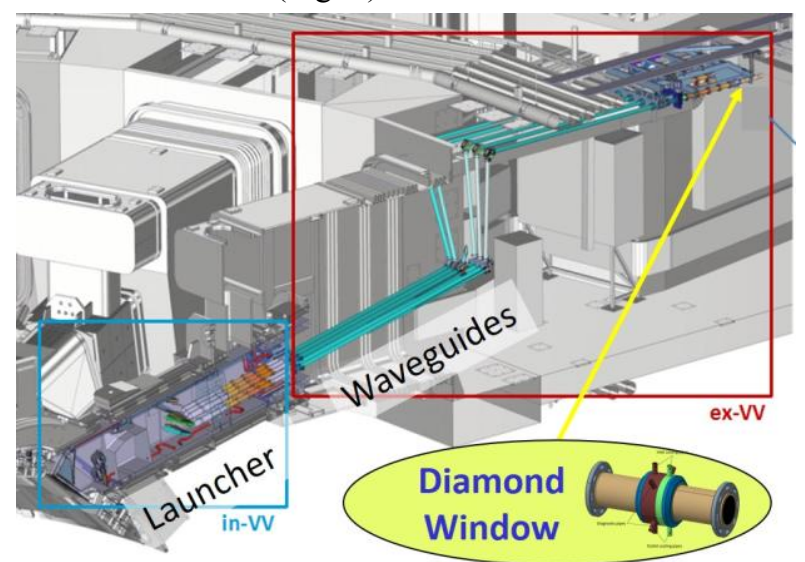

Fig. 1: ITER EC Upper Launcher and the ex-vessel MMW- system - location of the window in the port cell. In front of the window the Isolation Valve is located.
The window unit consists of a synthetic polycrystalline diamond disk (Ø $80 \mathrm{~mm}$ x $1.11 \mathrm{~mm}$ ) produced by 'Microwave Plasma Assisted (MPA)' chemical vapour deposition (CVD) mounted in a system of metallic parts. It is part of the first confinement system of ITER, which is a Nuclear Facility INB No. 174 and thus the window has the most stringent requirements in the ITER safety (SIC1/PIC1), quality and vacuum classifications.

As the design, the manufacturing and the qualification of the diamond window cannot be completely covered by standard codes, a specific qualification program has to be developed, which also includes prototyping activities. In the framework of a contract with F4E, KIT develops the testing and qualification program for a window prototype and will execute the prototype tests. [2][3]. The tests range from standard tests for geometry control, vacuum and leakage tests up to mm-wave-transmission tests for which a dedicated measurement facility (FABRY-PEROT-resonator) is available at KIT [3][1]. Based on the experience, which will be acquired during the prototyping phase, the final qualification for the serial windows will be defined. The qualification activities are supplemented by $R \& D$ activities focused on the mechanical properties of the diamond disk. 
Considering the high price, fracture tests with large area disks, as they will be used for the window, are not affordable. The price also defines the reduced number of disks. Five disks with a diameter of $30 \mathrm{~mm}$ and a thickness of $1.11 \mathrm{~mm}$ have been used to determine the flexural strength by a ring-on-ring test (geared to DIN 51105 [6]). In the following, the experimental set-up for the tests and the results will be presented. This work was performed in frame of a bachelor thesis (S. Dieterle).

In addition, a mock-up made of a diamond disk brazed to a copper cuff will be tested to determine the mechanical stability of the disk under vacuum operation conditions under different pressure scenarios. The same experiments are suitable to study the cyclic load behavior of the brazing joint between diamond disk surface and metallic copper cuff. But the main aim of the experiments is to give evidence that the diamond disk with a thickness of $1.11 \mathrm{~mm}$ can withstand the expected loads during its ITER life time. The respective program for the brazed mock-up pressure tests, which is under F4E and IO review, will be shortly presented.

\section{Fracture tests}

\subsection{Experimental method and materials}

The testing machine was a "Zwick/Roell" model "Z100" which was adapted with a loading mechanism constructed by KIT geared to DIN 51105. Fig. 2 shows the ring-on-ring test facility, while Fig. 3 shows in detail the schematic installation of the specimen and the rings.

\begin{tabular}{|l|l|l|}
\hline 2 & $\begin{array}{l}\text { Load ring } \\
\left(\mathrm{d}_{\text {load }}=5.4 \mathrm{~mm}\right)\end{array}$ \\
\hline 3 & $\begin{array}{l}\text { Support ring } \\
\left(\mathrm{d}_{\text {support }}=27 \mathrm{~mm}\right)\end{array}$ \\
\hline 4 & \begin{tabular}{l} 
Centring \\
\hline 5
\end{tabular} & $\begin{array}{l}\text { Holding fixture } \\
\text { connected to the } \\
\text { test machine (top) }\end{array}$ \\
6 & $\begin{array}{l}\text { Holding fixture } \\
\text { connected to the } \\
\text { test machine } \\
\text { (bottom) }\end{array}$ \\
\hline 7 & $\begin{array}{l}\text { Twist safety } \\
8\end{array}$ & $\begin{array}{l}\text { Pressure pipe } \\
9\end{array}$ \\
\hline 10
\end{tabular}

Fig. 2: Loading facility for the fracture tests.

Using the ring-on-ring test a thin disk is placed between two concentric rings with different diameter (load ring, support ring). The rings are compressed against each other up to the fracture of the disk.

It has to be guaranteed that both rings are adjusted to a possible wedge of the sample. For this purpose originally, a cardan joint was planned above the load ring but was not practicable. The wedge of the disks was very small and therefore a silicone foil, placed between the load ring and the specimen, was used as an alternative. In addition the support ring was placed on a silicone bearing in order to balance small imperfections (silicone parts were made of silicone with a SHORE-A hardness of 60 and a thickness of $0.6 \mathrm{~mm}$ ) (Fig. 3)

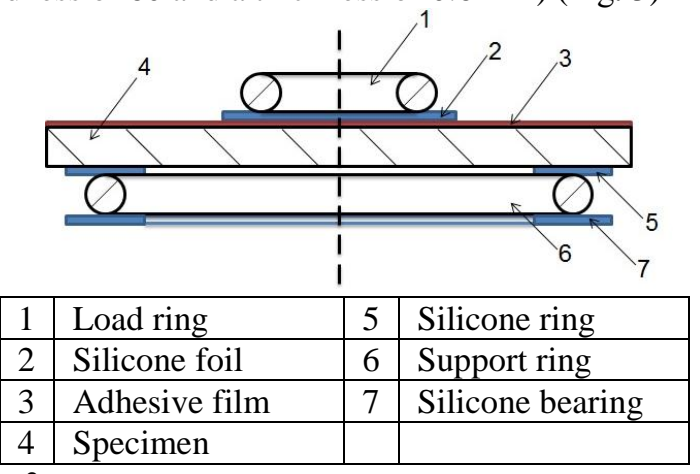

Fig. 3: Schematic installation of specimen and support ring.

Preliminary fracture tests with alumina have been made to adjust the alignment of the test rings, to match the installation as much as possible to DIN 51105 [6] and to test the reproducibility of the process.

To get conservative and more reliable results tensile stress was applied to the growth side (GS) of the diamond disk, being the mechanically more unstable surface [5], (i.e. the GS of each disk faced the callipers). The alignment of the test rings was matched to DIN 51105. To avoid disk sticking, the concentricity of the disk to the test ring was slightly beyond DIN 51105, but according to ASTM 1499 [7]. The force was applied with a rate of $50 \mathrm{~N} / \mathrm{s}$.

Five CVD diamond disks from "Diamond Materials GmbH (Freiburg)" were fractured (ER_Lot01,-02,-0306,-08). In advance to the fracture tests, the specimens were characterized. The thickness (height) was measured with a micrometer while the diameter was measured with a calliper gauge. Also the dielectric loss tangent of the samples was characterised.

Table 1: Specimen dimensions and loss tangent $(\tan (\delta))$.

\begin{tabular}{lcll}
$\begin{array}{l}\text { Specimen } \\
\text { ER_ }\end{array}$ & $\begin{array}{l}\text { Mean diameter } \\
/ \mathrm{mm}\end{array}$ & $\begin{array}{l}\text { Mean height } \\
/ \mathrm{mm}\end{array}$ & $\tan (\delta) /-$ \\
\hline Lot01 & $30.01 \pm 0.02$ & $1.111 \pm 0.002$ & $5.5 \cdot 10^{-6}$ \\
Lot02 & $30.01 \pm 0.02$ & $1.111 \pm 0.002$ & $6.0 \cdot 10^{-6}$ \\
Lot03 & $30.01 \pm 0.02$ & $1.107 \pm 0.002$ & $7.8 \cdot 10^{-6}$ \\
Lot06 & $29.98 \pm 0.02$ & $1.112 \pm 0.002$ & $5.5 \cdot 10^{-6}$ \\
Lot08 & $29.99 \pm 0.02$ & $1.111 \pm 0.002$ & $5.2 \cdot 10^{-6}$ \\
\hline
\end{tabular}

\subsection{Results of fracture tests}

The measured fracture forces were interpreted to be proportional towards the flexural strength in the ring-onring test. The formula (1) from DIN 51105 was used. It assumes linear elastic, homogeneous and isotropic material behaviour and thin plate theory [6][7].

$$
\sigma_{r r}=\frac{3 \cdot F}{2 \cdot \pi \cdot H^{2}}\left[(1+v) \cdot \ln \left(\frac{d_{2}}{d_{1}}\right)+(1-v) \cdot\left(\frac{d_{2}^{2}-d_{1}^{2}}{2 \cdot D^{2}}\right)\right]
$$

\begin{tabular}{|c|l|c|l|}
\hline$\sigma_{\mathrm{rr}}$ & Flexural strength & $v$ & Poisson's ratio \\
\hline $\mathrm{d}_{1}$ & Load ring diameter & $\mathrm{H}$ & Specimen height \\
\hline $\mathrm{d}_{2}$ & Support ring diameter & $\mathrm{F}$ & $\begin{array}{l}\text { Maximum force } \\
\text { at fracture }\end{array}$ \\
\cline { 1 - 2 } $\mathrm{D}$ & Specimen diameter & & \\
\hline
\end{tabular}

For the Poisson's ratio $v=0.1$ [8] was used. 
The flexural strength was determined to be $314.28 \mathrm{MPa}$ on average with a standard deviation of $\pm 16.19 \mathrm{MPa}$. The single values differed between $295.55 \mathrm{MPa}$ and $332.73 \mathrm{MPa}$.

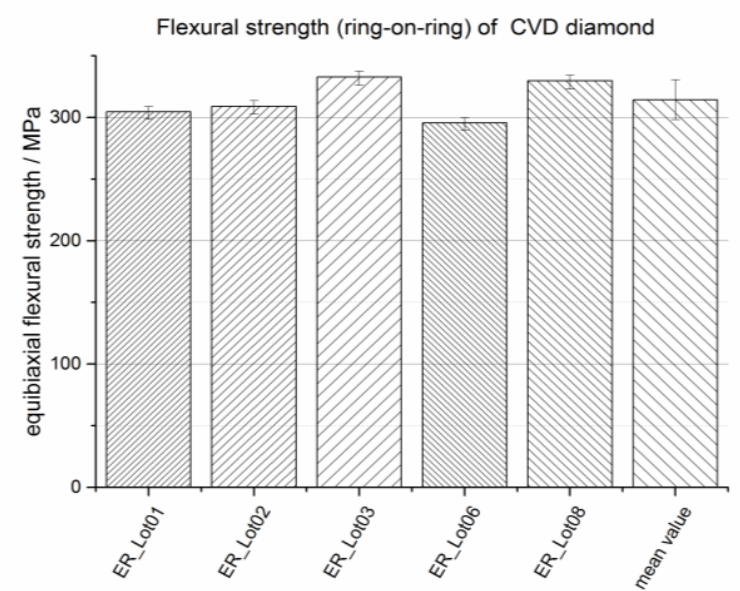

Fig. 4: Flexural strength of the CVD diamond disks

After the fracture tests, the disks consisted of 3-7 pieces. Fig. 5 shows the fracture patterns of the disks. Two cracks which did not lead to total fracture were also observed (arrows in Fig. 5). According to DIN 51105, the measurement is valid if possible origins of fracture are located within a circle around the axis of symmetry of the load ring with a diameter of $d=d_{\text {load }}+1 \mathrm{~mm}$, which was the case for ER_Lot01, 02, 03 and 06. For one specimen ER_Lot08 (disk No.6), two possible origins of fracture were located outside this area.

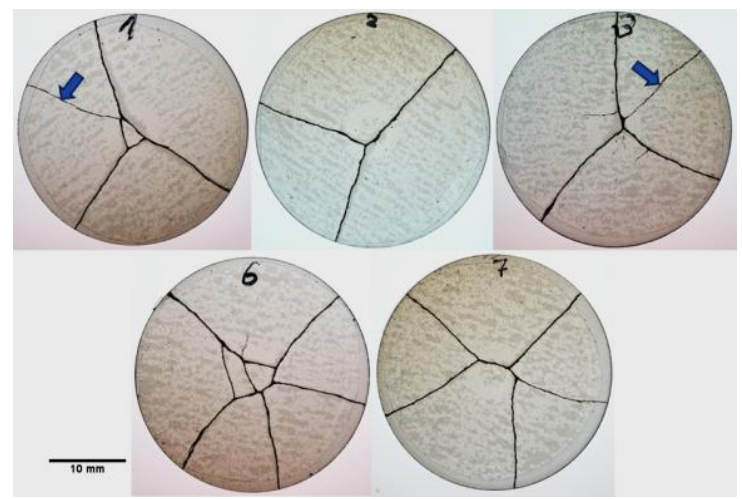

Fig. 5: Fracture patterns of the CVD diamond disks. (Specimen with No. '6' is ER_Lot08 while '7' is Lot06)

A two parameter WEIBULL statistics according to DIN EN 843-5 was performed and resulted in a characteristic WEIBULL strength of $\hat{\sigma}_{0}=321.29_{-20.17}^{+22.21} \mathrm{MPa}$ and a WEIBULL modulus of $\widehat{m}_{\text {cor }}=17.08_{-12.23}^{+11,20}$.

The deflection to rupture was $30.6 \mu \mathrm{m}( \pm 1.7 \mu \mathrm{m})$.

After the fracture tests, further investigation with a scanning electron microscope have been performed (see example in Fig. 6). The investigations of the fractured surfaces showed many large, flat areas. Inclusions cannot be completely excluded as possible origins of fracture, although direct proof lacks. The observations suggested intergranular fracture.

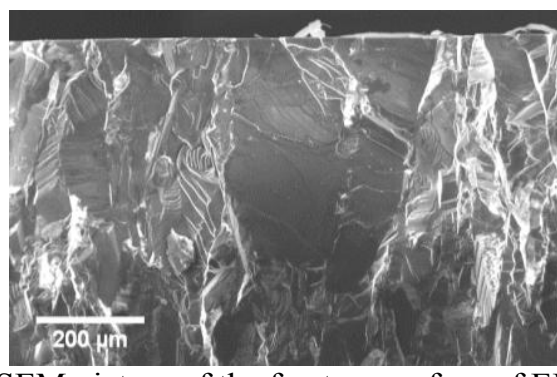

Fig. 6: SEM picture of the fracture surface of ER_Lot03

\subsection{Discussion of the fracture test results: error considerations, limitations and relevance for the ITER window}

The fracture test results have to be considered taking into account some boundary conditions. Potential, although not quantified, errors are possible with respect to the loading facility:

- Possible misalignment due to elastic or plastic deformation of the loading facility or other machine parts or due to geometric imperfections of both the testing fixture and the disks.

- $\quad$ Misalignment caused by possible tilt of parts.

The maximum analytically calculated errors for the flexural strength are about - 6.72 $\mathrm{MPa}$ and + 4.62 $\mathrm{MPa}$, considering errors in height, diameter and force measurements.

The flexural strength depends on the Poisson's ratio of the specimen. In literature [9], a second value for the Poisson's ratio $(v=0.0691)$ is available, which results in a slightly lower strength of the CVD diamond disks (reduced by approximately $6 \mathrm{MPa}$ ).

Further, the equations used are supposed to be (theoretically) valid only for perfect geometries (e.g. full circular contact between and optimal concentricity of rings and disk).

The equation to obtain flexural strength in its narrowest definition is only valid for an average grain size of $<100 \mu \mathrm{m}$. The grain sizes were not determined in this work but vary over the disk thickness.

For a statistical WEIBULL evaluation five tests are the minimum requirement and at least 30 tests are recommended in DIN EN 843-5 in order to obtain trustable parameters.

It's obvious that the scope of the work performed was not to evaluate a full statistics, but nevertheless a batch of 5 samples - due to the high price of the individual samples - gives adequate information about the mechanical stability.

Compared to literature [5], the flexural strength obtained in this work was lower, but the measurements of Klein [9] suggest smaller strength values than found in the actual work. The disk dimensions might surely influence the flexural strength, especially the disk thickness as the maximum grain size increases with increased thickness. A comparison of different experiments with different diamond disks is therefore difficult.

Translating the measured values with the ring-on-ring facility into other loading situations is another point.

The CVD diamond disks planned to be used in ITER will be located in a fixed restraint (disk brazed to a 
copper cuff) and the environmental conditions will be rather different.

FEM (finite element method) analyses of the window unit were carried out to check its structural integrity during normal operation, paying particular attention the diamond disk [10]. These analyses took into account also the residual stresses due to the cool down phase of the brazing process between disk and cuffs (high stresses because of temperature decrease from about $850^{\circ} \mathrm{C}$ to $20^{\circ} \mathrm{C}$ ). Normal ITER operation refers to the temperature distribution resulting from the transmission of the microwave beam, the dead weight, the fluid pressure in the cooling channels and the external atmospheric pressure acting on the unit.

In a conservative approach, performing an arithmetic sum of the principal stresses the maximum stress would result in $151 \mathrm{MPa}$ as shown in Fig. 7. This value is equal to the safe stress limit for diamond, that is assumed to be in the order of $150 \mathrm{MPa}$ (with an ultimate stress around 450-500 MPa based on [8], [11]). The calculated maximum stress is also significantly below the flexural strength determined in the actual experiments.

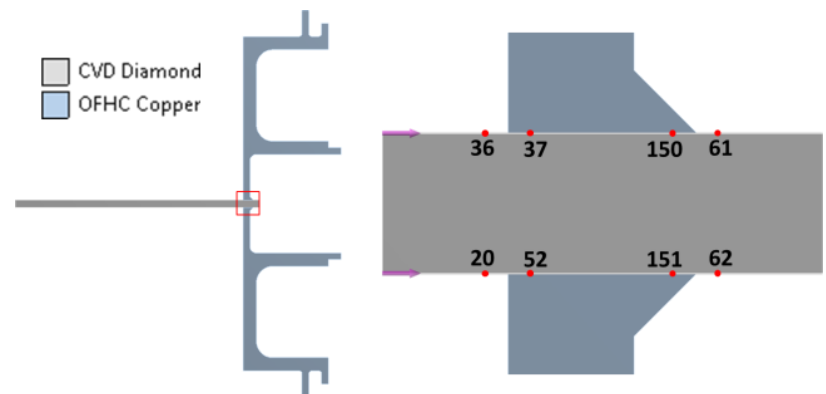

Fig. 7: Maximum principal stresses [in MPa] in the disk brazing zone at $51 \mu \mathrm{m}$ (red dots) distance from the singularity points for brazing plus operating condition.

However, to sum up, it needs to be emphasized that an entire extrapolation of the fracture test results towards the real geometry of the disk and its integration in the window unit is difficult. Therefore it is strongly recommended, especially for safety reasons, to perform as part of the window qualification, further tests, simulating the expected pressure loading conditions, by using disks in real scale $(\varnothing 80 \mathrm{~mm} \times 1.11 \mathrm{~mm})$, in real restraint and under real and accidental conditions of ITER. Such experiments, executed successfully, together with structural analyses of the window unit are required to verify the compatibility of the design.

As the final prototype is not yet manufactured pre-test with a brazed mock-up will support the qualification process and are introduced shortly in the next chapter.

\section{Pressure tests on a brazed diamond disk - test program and status of work}

The planned pressure tests on the brazed diamond mockup support the $R \& D$ work with the aim to gain further experience for later qualification of the window prototypes and the serial diamond windows. Information will be acquired on one hand on the mechanical stability of the diamond disk against high pressure loads and on the other hand on the "fatigue" of the brazing joint under cyclic load. The boundary conditions are tried to be similar but do not reflect completely the pressure loading conditions (during normal and off-normal events) of the window unit installed in the WG lines in ITER.

Fig. 8 shows the brazed mock-up which will be used for the tests. The diamond disk itself as well as the mock-up with the disk brazed to (simplified) copper cuffs were manufactured by Diamond Materials GmbH (Freiburg).

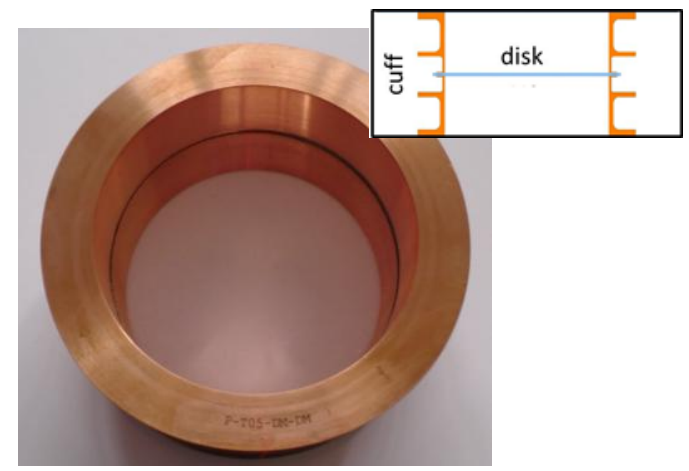

Fig. 8: Diamond disk ( $\varnothing 80 \mathrm{~mm}$ x $1.11 \mathrm{~m})$ brazed mockup. Laser engraving for specimen identification (P-T05$\mathrm{DM}$ ) is on the cuff connected to the GS side of the disk.

Following an ITER Requirement Note on the pressure cycles for torus diamond window (RN-52UL-017) different pressure gradient have been identified, which shall be simulated by the tests (Table 2 ). The pressure gradients are expected to be seen by the diamond disk during the various events expected during the window life time. These include leak tests and maintenance events as well as accidental events (Cat I-IV). The 2.0 bar torus pressure event (No.7) (Cat IV) is imposed by ITER Safety and corresponds to a combined failure of the pipe provoking the event and the VVPSS (vacuum vessel pressure suppression system). It is beyond the design basis for the window as it requires the additional failure of the EC isolation valve to close.

Table 2: List of pressure gradients and number of cycles. (a negative gradient corresponds to a higher pressure on the gyrotron side.)

\begin{tabular}{|c|c|c|c|}
\hline No. & $\begin{array}{c}\text { Event Codes } \\
\text { from RN17 }\end{array}$ & $\begin{array}{c}\text { Pressure } \\
\text { Gradient }\end{array}$ & $\begin{array}{c}\text { Number of } \\
\text { Cycles\# }\end{array}$ \\
\hline 1 & 1 & +0.12 bar & 610 \\
\hline $2 *$ & $2+6$ & $+10^{-3}$ bar & $3.5 \cdot 10^{3}$ \\
\hline 3 & $4 \mathrm{a}+5 \mathrm{a}+7+11 \mathrm{a}$ & $+0.1 \mathrm{bar}$ & 65 \\
\hline 4 & $4 \mathrm{~b}+5 \mathrm{~b}$ & $-0.1 \mathrm{bar}$ & 48 \\
\hline 5 & 8 & $+1.0 \mathrm{bar}$ & 1 \\
\hline 6 & 10 & $-1.0 \mathrm{bar}$ & 2 \\
\hline 7 & 12 & $+2.0 \mathrm{bar}$ & 1 \\
\hline
\end{tabular}

*will be neglected as the load is very low.

An automatic computer controlled vacuum system with several valves is used to perform reproducible pressure cycles. The principle set-up is shown in Fig. 9. The mock-up (1) is connected on both sides vacuum tight to the system. The lower part will be evacuated to a pressure level of $\mathrm{p}_{\mathrm{vac}}<10^{-5} \mathrm{mbar}$ by the high vacuum pump HP3. The pre-pump for the expansion to atmosphere is VP3 and monitoring is realized by the vacuum gauge P005 (Pfeiffer-PKR360, low current). The upper side of the mock-up can be loaded by pressure of nitrogen gas (3) or by vacuum (monitored with P001) 
applied by using a spiro-booster pump (VP2) and passing the valve V4. By operating valves V5 and V6, all states between atmospheric pressure and defined conditions according to Table 2 can be obtained. The respective switching operations of the valves are actuated by a computer program to which trigger points are given as input parameters. While for positive gradients the GS of the disk is orientated up, the mockup has to be turned for negative gradients.

The numbers of cycles in Table 2 will be multiplied by a test factor between 2 and 3 to have some safety margin.

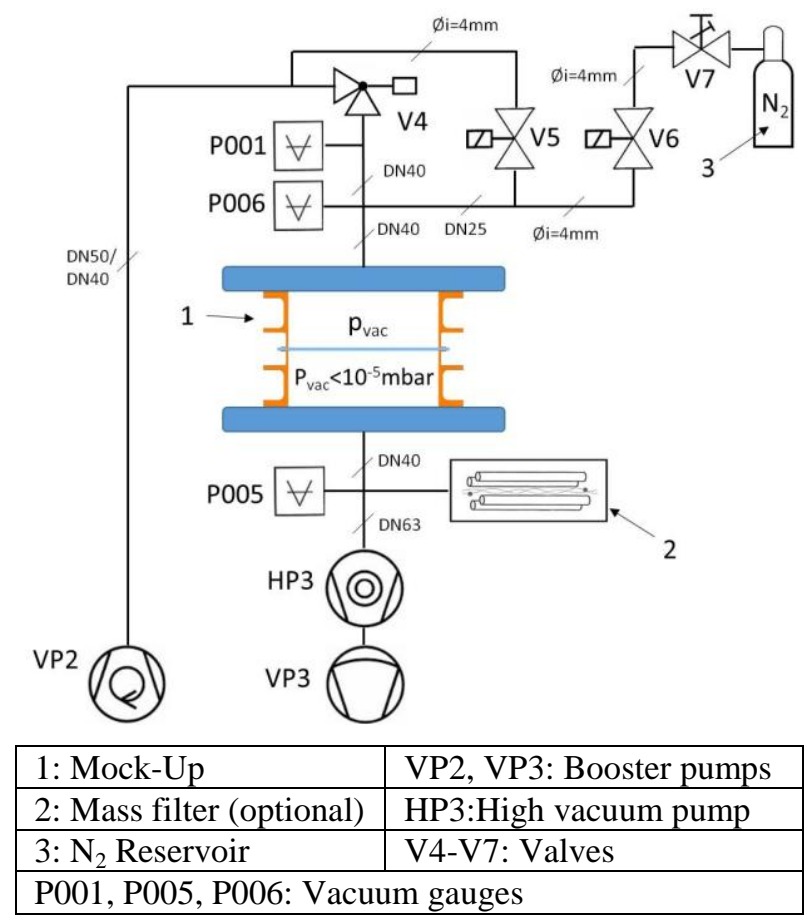

Fig. 9: Experimental setup for cyclic pressure tests

After each (cyclic) load case the leak tightness of the mock up will be checked using a standard leak tester and helium as tracer gas (requirement: $\leq 1 \cdot 10^{-9} \mathrm{mbar} \bullet 1 / \mathrm{s}$ ).

The pressure test with the maximum pressure of 2 bar will be only performed after successful performance of all cyclic tests. For this most critical experiment the pressure rise will be controlled by hand and it will finally show if the $1.11 \mathrm{~mm}$ disk, integrated into the cooper cuff, can cope with the high pressure load.

All tests need to be accompanied by the necessary quality procedures, i.e. all operations have to be described in detail, control plans have to be written and followed and certificates have to be available.

\section{Summary and Conclusions}

The diamond window of the ITER EC system is a Protection Important component and needs specific qualification. Respective test programs are under development and prototypical activities are ongoing. In addition experiments for determination of flexural strength have been performed with typical diamond disks of a thickness of $1.11 \mathrm{~mm}$ but with a reduced diameter. Five samples have been broken and the average flexural strength was $314 \mathrm{MPa}$. Making a direct projection to the ITER case, where the disk is implemented into a housing and exposed to the ITER operational and accidental condition is quite difficult. Therefore experiments simulating these conditions are necessary to proof the capability of the disk to withstand the expected loads. An experimental set-up is available at KIT to make cyclic and high pressure tests, the respective test program is under F4E and IO review and results are expected in near future.

\section{Acknowledgments}

This work was supported by Fusion for Energy under the service contract No F4E-OPE-467. The views and opinions expressed herein reflect only the author's views. Fusion for Energy is not liable for any use that may be made of the information contained therein.

\section{References}

[1] D. Strauss, et al, Progress of the ECRH upper launcher design for ITER, Fusion Eng. Des. 89, 2014, 1669-1673.

[2] S. Schreck, et al., ITER ECRH upper launcher torus diamond window - Prototyping, testing and qualification, Fusion Eng. Des. (2015), Volumes 9697, October 2015, Pages 593-596.

[3] S. Schreck, et al., ITER ECRH Upper Launcher: Test plan for qualification of the Diamond Torus Window Prototype III, Fusion Eng. Des. (2016), Volumes 109-111, Part B, 1 November 2016, Pages 1232-1236.

[4] F. Königer: Measurement system for the precise determination of dielectrical properties in the mmwave range based on hemispherical open resonators. Frequenz 43 (1989).

[5] R. Spörl, Einfluss des Gefüges auf mechanische Festigkeit und dielektrische Eigenschaften von CVD Diamant, Forschungszentrum Karlsruhe GmbH, Editor., 2001.

[6] Standard DIN 51105:2010-08: Advanced technical ceramics - Mechanical properties of monolithic ceramics at room temperature - Determination of flexural strength by the ring-on-ring test. Berlin: Beuth Verlag GmbH, 2010.

[7] Norm ASTM C1499-15: Standard test method for monotonic equibiaxial flexural strength of Advanced Ceramics at Ambient Temperature, West Conshohocken: ASTM International, 2015.

[8] M. Thumm, "Development of output windows for high-power long-pulse gyrotrons and ec-wave applications", International Journal of Infrared and Millimeter Waves, Vol. 12, No. 1, pp. 3-14, 1998.

[9] C. A. Klein, „Diamond windows and domes: flexural strength and thermal shock", Diamond and Related Materials, Bd. 11, pp. 218-227, 2002.

[10] G. Aiello et al., Design validation of the CVD diamond window unit for the ITER EC H\&CD Upper Launcher, Proceedings 9th International Workshop Strong Microwaves and Terahertz Waves: Sources and Applications 2014.

[11] M. Thumm, State of the Art of High Power GyroDevices and Free Electron Masers, KIT Scientific Reports 7717, Update2015. 